\title{
Associative interference in recognition memory: A dual-process account
}

\author{
MICHAEL F. VERDE \\ University of Massachusetts, Amherst, Massachusetts
}

\begin{abstract}
Associative interference from overlapping word pairs (A-B, A-D) reduces recall but has inconsistent effects on recognition. A dual-process account suggests that interference conditions reduce recollection but increase familiarity. This is predicted to increase recognition false alarms but have variable effects on recognition hits, depending on the relative contribution of recollection and familiarity. In three experiments that varied materials (sentences or random nouns) and test type (associative or pair recognition), interference conditions always increased recognition false alarms, but sometimes increased and sometimes decreased recognition hits. However, remember hits always decreased and know hits always increased with interference, patterns predicted of the recollection and familiarity processes, respectively. According to the dual-process view, a manipulation that affects the component processes in opposite ways can produce inconsistent patterns of recognition performance as the relative contribution of recollection and familiarity changes across tasks.
\end{abstract}

According to dual-process theories of recognition, two qualitatively different retrieval processes contribute to recognition memory (Atkinson \& Juola, 1974; Mandler, 1980; Reder et al., 2000; Yonelinas, 1994). The theories vary in detail, but their descriptions of the processes are generally similar. Recollection retrieves episodic or associative details. It is typically described as a search for specific information, a process perhaps similar to that involved in the recall task (Clark, 1999; Humphreys, 1978; Mandler, 1980). Familiarity produces nonspecific information about past occurrences. A retrieval cue matches each item in memory to some degree on the basis of similarity or learned association, and the global or aggregate match is represented psychologically as a unidimensional sense of familiarity strength.

The detrimental effect on recall of studying overlapping paired associates $\left(\mathrm{A}-\mathrm{B}, \mathrm{A}-\mathrm{D}\right.$ or $\left.\mathrm{A}-\mathrm{B}, \mathrm{A}-\mathrm{B}_{\mathrm{r}}\right)$ is well documented in the classic literature on proactive and retroactive interference. However, the same literature notes that evidence of associative interference in recognition is often absent, or at best inconsistent (for a review, see Postman, 1976). One way to conceptualize the associative interference paradigm is as a manipulation of the similarity between items (e.g., Dyne, Humphreys,

This work was completed while M.F.V. was supported by National Institutes of Health Training Grant MH16745-19. The present research was used in his doctoral dissertation at the University of Illinois, UrbanaChampaign, 2001. The author thanks Robert Greene, William Hockley, Caren Rotello, Deanne Westerman, and Bruce Whittlesea for helpful comments on a previous draft of this article, and Brian Ross, Bill Brewer, Neal Cohen, Gary Dell, and Art Kramer for their comments during the course of this research. Correspondence should be addressed to M. F. Verde, Department of Psychology, Box 37710, University of Massachusetts, Amherst, MA 01003-7710 (e-mail: mverde@psych.umass.edu).
Bain, \& Pike, 1990). Overlapping pairs (dog-tree, doglake) are more similar to one another than are nonoverlapping pairs (dish-skirt, star-ball). As a consequence, a recognition probe drawn from a study list of overlapping pairs has, on average, a greater match to items in memory than does a probe drawn from a study list of nonoverlapping pairs. As in the earlier interference literature, studies manipulating the relatedness of test probes to the study list have produced inconsistent findings. The present study describes a dual-process account that can shed light on these puzzling results.

Increasing the similarity or relatedness of nonstudied probes to the study list increases the false alarm rate. This has been observed with associatively, semantically, or orthographically related words (Anisfield \& Knapp, 1968; Roediger \& McDermott, 1995; Shiffrin, Huber, \& Marinelli, 1995; Underwood, 1965; Vogt \& Kimble, 1973), word pairs (J. R. Anderson \& Reder, 1999; Dyne et al.,1990), alphanumeric characters (Flagg, 1976; Reitman \& Bower, 1973), geometric shapes (Medin \& Schaffer, 1978), faces (Busey \& Tunnicliff, 1999; Vokey \& Read, 1992), pictures (Henkel \& Franklin, 1998; Koutstaal \& Schacter, 1997; Strack \& Bless, 1994), and sentences (Bransford \& Franks, 1971; Cantor \& Engle, 1993; Holmes, Waters, \& Rajaram, 1998; King \& Anderson, 1976; Reder \& J. R. Anderson, 1980). Increasing the similarity or relatedness of studied probes to the study list produces inconsistent results, sometimes slightly increasing the hit rate (Dyne et al., 1990; Shiffrin et al., 1995) and other times decreasing the hit rate (J. R. Anderson \& Reder, 1999; Cantor \& Engle, 1993; King \& J. R. Anderson, 1976; Reder \& J. R. Anderson, 1980).

Models of recall typically describe associative interference as a byproduct of a competitive retrieval process. Items in memory are sampled according to the degree of 
match between the item and the retrieval cue. Retrieving the target memory can be made more difficult when other, similar memories are also recruited by the cue (Gillund \& Shiffrin, 1984; Rundus, 1973; Wixted, Ghadisha, \& Vera, 1997). If recollection-based recognition involves a recall-like process, recollection should decrease under interference conditions. Models of familiaritybased recognition make a different prediction: Because the familiarity process is aggregative rather than competitive, increasing the number of items in memory that are similar to the target should increase global match and thus increase familiarity strength (Gillund \& Shiffrin, 1984; Hintzman, 1988).

The theoretical characteristics of the retrieval processes lead to two predictions that are consistent with the body of empirical data. First, familiarity and recollection of old items are affected in opposite ways by an interference manipulation, which can result in either an increase or decrease in hits, depending on the relative contribution of the two processes. Second, the familiarity (and perhaps false recollection) of new items should only increase with interference, resulting in an increase in false alarms. The next sections discuss these predictions in the context of word pair learning and outline the use of remember-know judgments to measure retrieval processes.

\section{Associative Interference and Retrieval Processes}

Consider a study list of six word pairs: tree-sand, tree-star, rose-bear, doll-bear, lake-bird, wine-snow. As shorthand, the words are represented by letters: A-B, A-C, D-E, F-E, G-H, I-J. Retrieval processes can be described in terms of the degree of match between a retrieval cue and representations in memory. Restricting the example to memory representations of the study list, there are three possible degrees of match between a word pair presented as a test probe and an item in memory (see Table 1). The match might be identical (I), sharing both words, a partial match $(\mathrm{P})$, sharing only one word, or a mismatch $(\mathrm{M})$, sharing no words - with the degrees of match ordered I $>\mathrm{P}>\mathrm{M}$. For example, the test probe $A-B$ is identical to one memory item (A-B), partially matches one memory item (A-C), and mismatches four memory items (D-E, F-E, G-H, I-J). The studied test probes $A-B$ and $G-H$ represent the interference and

Table 1

Degree of Match Between Probes and Memory

\begin{tabular}{lllllllll}
\hline \multirow{2}{*}{$\begin{array}{c}\text { Test } \\
\text { Probe }\end{array}$} & & Type & Condition & \multicolumn{6}{c}{ Items in Memory } \\
\cline { 3 - 8 } & A-B & A-C & D-E & F-E & G-H & I-J \\
\hline$A-B$ & studied & interference & $\mathrm{I}$ & $\mathrm{P}$ & $\mathrm{M}$ & $\mathrm{M}$ & $\mathrm{M}$ & $\mathrm{M}$ \\
$G-H$ & studied & baseline & $\mathrm{M}$ & $\mathrm{M}$ & $\mathrm{M}$ & $\mathrm{M}$ & $\mathrm{I}$ & $\mathrm{M}$ \\
$A-E$ & rearranged & interference & $\mathrm{P}$ & $\mathrm{P}$ & $\mathrm{P}$ & $\mathrm{P}$ & $\mathrm{M}$ & $\mathrm{M}$ \\
$G-I$ & rearranged & baseline & $\mathrm{M}$ & $\mathrm{M}$ & $\mathrm{M}$ & $\mathrm{M}$ & $\mathrm{P}$ & $\mathrm{P}$ \\
$K-L$ & novel & & $\mathrm{M}$ & $\mathrm{M}$ & $\mathrm{M}$ & $\mathrm{M}$ & $\mathrm{M}$ & $\mathrm{M}$ \\
\hline
\end{tabular}

Note-The degree of match between a recognition probe and an item in memory can be described as identical (I), a partial match (P), or a mismatch (M), with $\mathrm{I}>\mathrm{P}>\mathrm{M}$. baseline conditions, respectively. Interference condition studied pairs overlap other pairs in the study list, whereas baseline condition pairs contain words that appear only once in the study list. Rearranged pairs, which serve as lures in associative recognition tasks, may likewise represent interference and baseline conditions depending on whether their component words are drawn from interference studied pairs $(A-E)$ or baseline studied pairs $(G-I)$.

The familiarity process produces a nonspecific sense of oldness based on the match between a cue and the contents of memory. Global match is an aggregate of all individual cue-to-memory matches (e.g., Gillund \& Shiffrin, 1984; Hintzman, 1988), and can be represented by a value on the unidimensional scale of familiarity strength. ${ }^{1}$ From Table 1 , it is clear that familiarity strength is greater for interference pairs relative to baseline pairs. This is true for both studied pairs and rearranged pairs. Interference pairs are more familiar because they partially match more items in memory.

The recollection process produces specific information about associations or past episodes, and this requires identifying or isolating a particular item in memory. Recall is used here as a guide to recollection-based retrieval (Clark, 1999; Mandler, 1980). Many models of recall suggest that competitive interference is a defining characteristic of retrieval (Gillund \& Shiffrin, 1984; Rundus, 1973; Wixted et al., 1997). Competitive interference is the idea that selectively retrieving a particular memory item becomes more difficult when competitors are also recruited by the retrieval cue. Nontarget items that closely match the target are also likely to be recruited by the cue, making them strong competitors. In Table 1, probes from the interference condition partially match more items in memory, leading to an increase in competitive interference and a reduced likelihood of retrieving the target memory.

The defining characteristics of familiarity (aggregation) and recollection (competitive selection) determine how the individual processes should be affected under conditions of associative interference. Predicting the effect of interference on recognition performance, however, is not straightforward. The dual-process view suggests that recognition hit rate is determined by both recollection and familiarity (see also Joordens \& Hockley, 2000; Reder et al., 2000). Under interference conditions, old items are expected to have greater familiarity strength but a reduced likelihood of recollection. The net effect of these opposing tendencies on hit rate depends on the relative contribution of familiarity and recollection to recognition judgments.

Whether recognition false alarm rate is also determined by both processes or is based on familiarity alone depends on the model of recollection. If recollection is high threshold (e.g., Yonelinas, 1994), so that recollection may never occur for a new item, false alarm rate is based only on familiarity and should increase under interference conditions. Alternatively, recollection is graded rather than all- 
or-nothing. It is known that source memory can be partial. For example, it is possible to accurately recall that a word was spoken by a male voice without being able to recall the specific male voice (Dodson, Holland, \& Shimamura, 1998). Similarly, recollections of past episodes might vary in the quantity and quality of detail. If recollective information is graded, a decision process is likely to be involved: The respondent compares the retrieved information with the cue and decides whether it constitutes an acceptable match. False recollection might arise when a nontarget memory similar to the target is retrieved and judged to sufficiently match the cue. Evidence suggests that false recollections occur when new items are very similar to studied items (Roediger \& McDermott, 1995). If false recollection leads to false alarms in this way, interference conditions, which increase the match of nontarget memories to the cue, should also increase recollectionbased false alarms.

\section{Remember-Know}

The dual-process account predicts that associative interference conditions should increase recognition false alarm rates but have a variable effect on hit rates. However, the account predicts not just the pattern of overall recognition but also effects on the component processes. With memory for old items, in particular, the recognition hit rate does not allow direct examination of the claim that opposing tendencies in recollection and familiarity cause the inconsistent hit rate patterns. To allow a more compelling test of the dual-process account, recognition was supplemented by remember-know judgments as a way to separately measure recollection and familiarity. After judging an item to be from the study list, subjects indicated whether they remembered specific details about the past encounter or simply knew, in the absence of such detail, that the word was old or familiar (Tulving, 1985; for a review, see Gardiner \& Richardson-Klavehn, 2000).

The experiential states of remembering and knowing have often been linked, directly or indirectly, to the theoretical retrieval processes of recollection and familiarity. The similarities between the two sets of constructs are obvious at the descriptive level: Recollection and remembering are associated with specific information, whereas knowing and familiarity deal with a nonspecific sense of past experience. A qualitative difference between remembering and knowing is suggested by evidence that remembering is tied to accurate memory for source and associations (Conway \& Dewhurst, 1995; Hockley \& Consoli, 1999; Mather, Henkel, \& Johnson, 1997; Perfect, Mayes, Downes, \& Van Eijk, 1996; but see Hicks, Marsh, \& Ritschel, 2002) and that remembering and knowing have different neurophysiological correlates (Curran, Gardiner, Java, \& Allen, 1993; Duzel, Yonelinas, Mangun, Heinze, \& Tulving, 1997; Rugg, Schloerscheidt, $\&$ Mark, 1998).

Using remember-know judgments to isolate the contribution of different processes requires assumptions, first about the way that the retrieval processes interact to produce the final recognition decision, and second about the relationship between subjective measures and the underlying processes. The assumptions adopted here are common in the literature. First, it is assumed that when recollection is available, it will solely determine the recognition judgment. Thus, the output of the recollection process is never reduced by increases in the output of the familiarity process. This assumption of priority suggests that if remembering is a product of the recollection process, it should provide a direct measure of the contribution of recollection.

A complication arises if, as was suggested earlier, recollection is subject to decision processes. In fact, it has been shown that the decision criterion for remember responses can be manipulated (Hirshman \& Henzler, 1998; Postma, 1999; Xu \& Bellezza, 2001), which indicates that remembering should not be treated as an absolute measure of recollection. However, it can serve as a relative measure of recollection when the criterion for recollection remains fixed across conditions within the same test list. It is a standard assumption that subjects maintain a single set of decision criteria within the same test list, and empirically it has been shown that subjects are reluctant to use multiple sets of criteria when only memory strength is manipulated within a list (Morrell, Gaitan, \& Wixted, 2002; Stretch \& Wixted, 1998), as was the case in the present experiments.

While the rate of remembering may serve as a direct measure of recollection, a similar measure of familiarity is problematic. The difficulty arises because rememberknow judgments are exclusive; there is no way for a subject to indicate a state of simultaneously remembering and knowing. Yonelinas and Jacoby (1995) have suggested that recollection and familiarity are independent. If this is so, and given the priority of recollection, the know rate will underestimate the contribution of familiarity whenever the remember rate is greater than zero. If the processes are independent, properly measuring familiarity requires a correction of the know rate: independent know $(\mathrm{IK})=[\mathrm{know} /(1-$ remember $)]$. In the present study, only analyses of IK rates are reported, although analyses of untransformed know rates produced identical results in every case.

\section{Overview of Experiments}

The dual-process account makes predictions at the level of recognition judgments and also at the level of remember-know judgments. With memory for old items, interference conditions are predicted to have opposing effects on the retrieval processes, so that recognition hit rate might increase or decrease, depending on the relative contribution of the component processes. However, interference should always decrease remember hit rate and increase IK hit rate, regardless of the effect on recognition hit rate. With new items, interference conditions are predicted to increase recognition false alarm rate because familiarity and false recollection should only increase with interference. The dual-process account can 
explain the puzzlingly inconsistent patterns of recognition observed in the empirical data. The goal of the present experiments was to test the dual-process account by reproducing the different patterns of recognition performance (an increase or decrease in hits with an increase in false alarms). If the account is correct, the predicted effects of interference on remember-know judgments (decrease in remember hits and increase in know hits) should be observed across all patterns of recognition.

The experiments were also designed to rule out alternative explanations for the inconsistent recognition patterns based on differences in materials and tasks. Increases in both hit and false alarm rates with interference were observed by Dyne et al. (1990) with random word pairs and by Shiffrin et al. (1995) with semantically, phonemically, and orthographically related single words. These writers argued that the observed pattern was consistent with familiarity-based models. Dyne et al., however, suggested that sentence materials might encourage the use of a recollective process, leading to recognition patterns not in keeping with familiarity-based models. In fact, studies using sentence materials have observed the decrease in hit rate (Cantor \& Engle, 1993; King \& Anderson, 1976; Reder \& Anderson, 1980). To rule out this material-specific explanation, it must be shown that an interference manipulation can both increase and decrease recognition hit rate with sentence materials (Experiments 1 and 2).

When word pairs are studied, two types of recognition test are possible. Associative recognition requires discriminating intact from rearranged pairs. All pairs contain words that were encountered during study, so discrimination must rely on memory for associations rather than on the familiarity of individual words. ${ }^{2}$ Pair recognition, on the other hand, requires discriminating studied pairs from novel pairs of unstudied words. Discrimination can rely on the familiarity of individual words. Associative recognition often behaves differently than recognition of old versus novel items (Clark, 1992; Nobel \& Shiffrin, 2001; Rotello \& Heit, 2000; Westerman, 2000, 2001; Yonelinas, 1997), which raises the possibility that each task relies on a different (single) retrieval process. To rule out this taskspecific explanation, it must be shown that an interference manipulation can both increase and decrease hit rate in associative recognition (Experiments 1 and 3).

\section{EXPERIMENT 1}

Subjects studied sentences in the form "the person is in the location." For example, "the doctor is in the garage." In the baseline condition, each person noun and location noun appeared only once in the study list. In the interference condition, each noun appeared four times during study, each time paired with a different person or location. The study list was followed by an associative recognition test in which studied sentences had to be discriminated from those containing persons and locations from the study list that had been rearranged into novel pairings.
Table 2

Experiment 1: Hit and False Alarm Rates

\begin{tabular}{lcccc}
\hline Judgment & H-B & H-I & FA-B & FA-I \\
\hline Recognition & .77 & .68 & .08 & .31 \\
Remember & .59 & .39 & .02 & .08 \\
Know & .18 & .29 & .06 & .23 \\
IK & .39 & .49 & .06 & .25 \\
\hline
\end{tabular}

Notes - Hit rates for baseline $(\mathrm{H}-\mathrm{B})$ and interference $(\mathrm{H}-\mathrm{I})$ pairs and false alarm rates for baseline (FA-B) and interference (FA-I) pairs are shown for overall recognition and also conditional on subjective state. $\mathrm{IK}=\mathrm{know} /(1-$ remember $)$.

\section{Method}

Subjects. Thirty-six undergraduates from the University of Illinois, Urbana-Champaign, participated in the study for course credit.

Materials and Design. The subjects were individually assigned to computers, which controlled list generation, presentation, and response recording. The assignment of nouns to experimental conditions and the order of items within lists were uniquely randomized for each subject. The stimuli were sentences in the form "the person is in the location." The person nouns and location nouns, representing 40 common professions and 40 everyday locations, were 4 to 12 letters in length and drawn from a pool of 72 person nouns and 72 location nouns.

There were 64 unique sentences in the study list. Half contained person and location nouns that appeared only once in the study list (baseline condition), while the other half contained person and location nouns that each appeared in four different sentences (interference condition). To create interference condition pairs, four person nouns and four location nouns were combined in all possible ways to yield 16 unique sentences. There were two such interference sets and 128 unique sentences in the test list: 64 studied sentences and 64 rearranged sentences. The latter were created by re-pairing either two studied nouns from different baseline pairs (baseline condition) or two studied nouns from different interference sets (interference condition).

Procedure. The 45-min session consisted of a practice phase, a study phase, and a test phase. During the practice phase, the subjects were given 10 study trials and 20 test trials to familiarize them with the task. The procedure was identical to the subsequent study and test phases, but practice materials never appeared again.

During the study phase, each sentence appeared in the center of the screen for 4,500 msec, followed by a 1,000-msec blank interval. The subjects were instructed to learn the sentences for a memory test to follow. During the test phase, each trial began with a fixation line of "+" symbols displayed in the center of the screen for $1,000 \mathrm{msec}$. A test sentence replaced the fixation line and remained until the subject responded. The "z" and "/" keys were used to report intact-rearranged recognition judgments. If a pair was judged to be intact, the " 1 " and " 2 " keys were used to report whether the memory was remembered or known. The trial ended with a 500msec blank screen. Remember-know instructions were adapted from standard ones used by Gardiner, Ramponi, and RichardsonKlavehn (1998). To summarize, the subjects were told that remembering is the ability to consciously bring back details of the study episode, such as where in the study list an item had appeared or what images or associations it had invoked at the time, and that knowing is a sense of familiarity in the absence of such detail.

\section{Results}

Hit and false alarm rates are shown in Table 2. Accuracy based on recognition hits and false alarms was reliably lower in the interference $\left(d^{\prime}=1.14\right)$ than in the 
baseline condition $\left[d^{\prime}=2.37, t(35)=10.54, p<.001\right]$. For studied pairs, the interference condition produced a decrease in recognition hits $[t(35)=3.41, p<.001]$, a decrease in remember hits $[t(35)=7.26, p<.001]$, and an increase in IK hits $[t(35)=2.14, p<.05]$. For rearranged pairs, the interference condition produced an increase in recognition false alarms $[t(35)=7.74, p<$ $.001]$, an increase in remember false alarms $[t(35)=4.22$, $p<.001]$, and an increase in IK false alarms $[t(35)=$ $6.52, p<.001]$.

\section{Discussion}

Given the characteristics of the retrieval processes, it was predicted that interference conditions would reduce the likelihood of recollecting old items but increase their familiarity strength. Consistent with this, remember hit rate decreased whereas IK hit rate increased in the interference condition. The increase in IK false alarm rate with interference was also consistent with an increase in familiarity, whereas the increase in remember false alarm rate suggests that subjects may have claimed recollection for rearranged pairs due to high similarity of those pairs to memories of studied items.

The pattern of decreasing recognition hit rate and increasing false alarm rate is similar to that observed in other studies using materials consisting of paired associates embedded in sentences. It might be that this pattern of recognition effects, specifically the decrease in hit rate, is tied to the sentence materials, as Dyne et al. (1990) suggest. Sentences, perhaps due to differences in their encoding, might lead subjects to use a different retrieval process than they would use for less meaningful materials. The dual-process account makes a different claim: The same retrieval processes are involved across recognition tasks, regardless of the materials. However, differences in tasks or materials may lead to differences in the relative contribution of recollection and familiarity, and the latter determines whether recognition hit rate increases or decreases under interference conditions.

\section{EXPERIMENT 2}

The goal of Experiment 2 was to show that sentence materials like those used in Experiment 1 can produce an increase rather than a decrease in recognition hit rate under interference conditions. Experiment 2 was identical to Experiment 1 in all important respects, save one: The test was pair recognition, which requires discriminating studied pairs from pairs containing completely novel words. Unlike in associative recognition, in pair recognition it is possible to accurately discriminate on the basis of the familiarity of individual words in a pair. The greater role of familiarity may push the pattern of recognition judgments toward that expected of a familiarity process - namely, an increase in both hit and false alarm rates. If this were to happen, the dual-process account still predicts a decrease in remember hit rate and an increase in IK hit rate.

\section{Method}

Subjects. Thirty-seven undergraduates from the University of Illinois, Urbana-Champaign, participated in the study for course credit.

Materials and Design. The materials and design were identical to Experiment 1 in all respects. The person and location nouns consisted of 72 common professions and 72 everyday locations. As in Experiment 1, there were 64 unique sentences in the study list and 128 unique sentences in the test list: 64 studied sentences and 64 novel sentences. The novel sentences were created from 32 persons and 32 locations that never appeared during study. Each novel sentence was included twice, for a total of 64 new sentences. Novel sentences were repeated to ensure that mere knowledge that a noun had been repeated in the test list (as was the case for old sentences in the interference condition) was not sufficient evidence that a sentence was old.

Procedure. The procedure was identical to Experiment 1 in most respects. However, pilot work indicated that using novel rather than rearranged lures led to performance close to ceiling, preventing a test of the critical hypotheses. Therefore, study duration in Experiment 2 was reduced to $3,000 \mathrm{msec}$ per sentence, bringing performance to the level observed in Experiment 1.

\section{Results}

Hit and false alarm rates are shown in Table 3. Accuracy based on recognition hits and false alarms was reliably higher in the interference condition $\left(d^{\prime}=2.50\right)$ than in the baseline condition $\left[d^{\prime}=2.04 ; t(36)=5.17, p<.001\right]$. For studied pairs, the interference condition produced an increase in recognition hits $[t(36)=4.99, p<.001]$, a decrease in remember hits $[t(36)=3.89, p<.001]$, and an increase in IK hits $[t(36)=8.94, p<.001]$. There was only one class of new items, so false alarms required no analysis.

\section{Discussion}

Unlike in Experiment 1, there was an increase (rather than a decrease) in recognition hit rate for the interference condition. However, the pattern of remembering and knowing remained unchanged. As predicted by the dual-process account, interference led to a decrease in remember hit rate and an increase in IK hit rate. The reversal in the direction of recognition hit rate came from using novel rather than rearranged lures. This may have allowed subjects to rely more on familiarity, because a sense of oldness for individual words is discriminative in pair recognition but provides little useful information in associative recognition. It is also possible that the reduction in presentation duration at encoding (needed to avoid ceiling performance in this easier memory task)

Table 3

Experiment 2: Hit and False Alarm Rates

\begin{tabular}{lccr}
\hline Judgment & H-B & H-I & FA \\
\hline Recognition & .71 & .83 & .11 \\
Remember & .53 & .42 & .02 \\
Know & .18 & .41 & .07 \\
IK & .38 & .71 & .08 \\
\hline
\end{tabular}

Notes-Hit rates for baseline $(\mathrm{H}-\mathrm{B})$ and interference $(\mathrm{H}-\mathrm{I})$ pairs and false alarm (FA) rates are shown for overall recognition and also conditional on subjective state. IK $=$ know/ $(1-$ remember $)$. 
reduced recollection, although rates of remembering were comparable to those in Experiment 1. Whatever the case, the results support the conclusion that the relative contribution of recollection and familiarity, and not the materials per se, determines whether interference conditions increase or decrease recognition hit rate. Put another way, interference reduced recollection of studied pairs but increased the contribution of familiarity to such an extent that the net effect was an increase in recognition hits.

Of course, the two patterns of recognition observed in Experiments 1 and 2 were each associated with a different type of recognition test. It might be that associative recognition depends on a retrieval process different from the one used in pair recognition. This possibility is amenable to a single-process account, whereas the dual-process account claims that different recognition tasks rely on the same processes. The relative contribution of recollection and familiarity may differ across tasks, which determines whether recognition hit rate increases or decreases under interference conditions.

\section{EXPERIMENT 3}

The goal of Experiment 3 was to show that an associative recognition test like that used in Experiment 1 can produce an increase rather than a decrease in recognition hit rate under interference conditions. Rather than meaningful sentences, study materials consisted of randomly paired nouns. Dyne et al. (1990) suggested that such materials should reduce the use of a recollective process. The greater role of familiarity may push the pattern of recognition judgments toward that expected of a familiarity process: an increase in both hit and false alarm rates. If this were to happen, the dual-process account still predicts a decrease in remember hit rate and an increase in IK hit rate. In Experiment 3, performance was compared across three different levels of interference: Words appeared in two, three, or four different pairs during study.

\section{Method}

Subjects. Thirty-one undergraduates from the University of Illinois, Urbana-Champaign, participated in the study for course credit.

Materials and Design. The subjects were individually assigned to computers, which controlled list generation, presentation, and response recording. The assignment of nouns to experimental conditions and the order of items within lists were uniquely randomized for each subject. The stimuli were randomly paired nouns drawn from a pool of 400 nouns matched for frequency $(<100$ /million; Kučera $\&$ Francis, 1967) and length (five to six letters).

There were 100 word pairs in the study list. Three conditions represented different levels of interference. In the low-interference condition, two words were assigned the left position, two words were assigned the right position, and all possible combinations of left and right position yielded 4 unique pairs (each word appeared in 2 pairs). In the medium-interference condition, three words were assigned the left position, three words were assigned the right po- sition, and all possible combinations of left and right position yielded 9 unique pairs (each word appeared in 3 pairs). In the highinterference condition, four words were assigned the left position, four words were assigned the right position, and all possible combinations of left and right position yielded 16 unique pairs (each word appeared in 4 pairs). The study list included similar numbers of pairs from each interference condition (32 low, 36 medium, 32 high).

There were 200 unique word pairs in the test list: 100 studied pairs and 100 rearranged pairs. The latter were created by rearranging pairs from the study list. Words were re-paired with other words from the same study condition. Thus, three classes of rearranged pairs were defined by whether the words were taken from low-, medium-, or high-interference studied pairs.

Procedure. The procedure was identical to that in Experiment 1. Study duration for each word pair was $4,000 \mathrm{msec}$.

\section{Results}

Hit and false alarm rates are shown in Table 4. Analyses were carried out using repeated measures analyses of variance. Accuracy based on recognition hits and false alarms reliably decreased with increasing levels of interference $\left[d^{\prime}\right.$, low $=1.67$, medium $=1.40$, high $=1.28$; $\left.F(2,60)=5.98, M S_{\mathrm{e}}=0.205, p<.01\right]$. For studied pairs, increasing levels of interference produced a slight increase in recognition hits that was marginally reliable $\left[F(2,60)=2.61, M S_{\mathrm{e}}=0.010, p<.10\right]$, a reliable decrease in remember hits $\left[F(2,60)=8.81, M S_{\mathrm{e}}=0.008\right.$, $p=.001]$, and a reliable increase in IK hits $[F(2,60)=$ $\left.9.26, M S_{\mathrm{e}}=0.024, p<.001\right]$. For rearranged pairs, increasing levels of interference produced a reliable increase in recognition false alarms $\left[F(2,60)=22.44, M S_{\mathrm{e}}=\right.$ $0.007, p<.001]$, a marginally reliable increase in remember false alarms $\left[F(2,60)=2.78, M S_{\mathrm{e}}=0.001, p<\right.$ $.10]$, and a reliable increase in IK false alarms $[F(2,60)=$ $\left.21.26, M S_{\mathrm{e}}=0.006, p<.001\right]$.

\section{Discussion}

Unlike in Experiment 1, there was an increase (rather than a decrease) in recognition hit rate with increasing interference. However, the same pattern of remembering and knowing was observed in both previous experiments. As predicted by the dual-process account, interference led to a decrease in remember hit rate and an increase in IK hit rate. The reversal in the direction of recognition hit rate came from using noun pairs rather than sentences. With less meaningful stimuli, recollection may be reduced so that familiarity plays a greater role. The results support

Table 4

Experiment 3: Hit and False Alarm Rates

\begin{tabular}{lcccccc}
\hline Judgment & H-Low & H-Med & H-High & FA-Low & FA-Med & FA-High \\
\hline Recognition & .66 & .65 & .71 & .16 & .21 & .29 \\
Remember & .49 & .45 & .39 & .03 & .04 & .05 \\
Know & .17 & .21 & .31 & .13 & .17 & .24 \\
IK & .35 & .37 & .51 & .13 & .18 & .26
\end{tabular}

Notes-Hit (H) and false alarm (FA) rates for low-, medium-, and highinterference conditions are shown for overall recognition and also conditional on subjective state. IK $=$ know/ $(1-$ remember $)$. 
the conclusion that the relative contribution of recollection and familiarity, and not the type of recognition task per se, determines whether interference conditions increase or decrease recognition hit rate. As in Experiment 2 , interference reduced recollection of studied pairs but increased the contribution of familiarity to such an extent that the net effect was an increase in recognition hits.

\section{GENERAL DISCUSSION}

In the recall literature, associative interference refers to the adverse effect on recall of studying overlapping word pairs $\left(\mathrm{A}-\mathrm{B}, \mathrm{A}-\mathrm{D}\right.$ or $\left.\mathrm{A}-\mathrm{B}, \mathrm{A}-\mathrm{B}_{\mathrm{r}}\right)$. In recognition, increasing the degree of overlap between pairs can be thought of as increasing the similarity or relatedness between studied items, a manipulation that typically increases recognition false alarm rate but has variable effects on hit rate. The different patterns observed in the literature were reproduced in the present study. Whereas an increase in the overlap between studied pairs always produced more recognition false alarms, it led to fewer recognition hits in Experiment 1 but more hits in Experiments 2 and 3.

According to the dual-process account, interference conditions decrease the likelihood of recollecting an old item but increase its familiarity strength. The net effect of these opposing tendencies can be either an increase or a decrease in recognition hit rate, depending on the relative contribution of the two processes to the memory judgment. For example, reducing the relative contribution of recollection makes it more likely that recognition performance follows a pattern predicted of the familiarity process. Consistent with this, reducing recollection by using pair recognition rather than associative recognition (Experiment 2) or random noun pairs rather than meaningful sentences (Experiment 3) led to an increase in hits with interference. The dual-process account was further supported by the finding that despite inconsistent effects on recognition hits, interference conditions consistently decreased remember hits and increased know (IK) hits, patterns expected of the retrieval processes that were tied to these subjective states.

Advocates of the dual-process view have noted a number of puzzling phenomena that can be understood in terms of the interaction of component processes. For example, the initial increase and then decrease of false alarms to related lures is evidence of the opposition of a fast familiarity process followed by a slower recall-toreject process (Hintzman, Caulton, \& Levitin, 1998; Hintzman \& Curran, 1994; McElree, Dolan, \& Jacoby, 1999). Closer to the present findings, manipulating the contribution of recollection and familiarity to recognition hit rate can lead to the appearance or disappearance of the word frequency mirror effect (Joordens \& Hockley, 2000; Reder, Angstadt, Cary, Erickson, \& Ayers, 2002) and the retrieval practice effect (Verde, 2004). The approach taken in the present study was to show that understanding the mechanisms of retrieval can be useful for generating predictions about the behavior of recollection and familiarity under various conditions. The remaining discussion considers alternatives to the dualprocess account offered here.

\section{Single-Process Account}

Some theorists suggest that remember-know judgments reflect only a quantitative and not a qualitative distinction, a view most often expressed in terms of a singleprocess signal detection (SPSD) model (Donaldson, 1996; Hirshman, 1998; Hirshman \& Master, 1997; Inoue \& Bellezza, 1998). In this model, recognition judgments are made by placing a decision criterion somewhere along the dimension of familiarity strength. Items with familiarity strength greater than criterion are judged to be old. Remembering merely reflects a second, more conservative criterion, describing items that are not only old but especially familiar. The SPSD model is extremely flexible, and in its unconstrained form (the placement of decision criteria and the characteristics of familiarity strength distributions are all free parameters) can be fit to any set of data. Providing the model with explanatory and not just descriptive power, however, requires examining how it fares when constrained either theoretically or by existing data.

A large body of work is based on the single-process, familiarity-based view of recognition (e.g., Clark \& Gronlund, 1996). Some critics have noted that fitting the SPSD model to remember-know data often requires parameter values that are odd or implausible in the context of this literature (Gardiner \& Gregg, 1997; Rotello, Macmillan, \& Reeder, 2004). Research on how people choose their decision criterion in recognition can also serve to constrain the SPSD model. Although it is clear that people do vary their recognition criterion depending on the task and materials, two more specific questions are relevant to the SPSD account.

The first is whether people shift their criterion on a trial-to-trial basis, using different criteria for different classes of items intermixed within the same test list. Subjects have been observed to do this as a result of marked changes in procedure between trials (Heit, Brockdorff, \& Lamberts, 2003; Hockley \& Niewiadomski, 2001; Verde \& Rotello, 2003), or with distinct types of items that recruit metamemory strategies (Whittlesea \& Williams, 2001). However, when classes of items differ only in their experimentally manipulated memory strength, as was the case in the present experiments, subjects do not seem to change their criterion from trial to trial (Morrell et al., 2002; Stretch \& Wixted, 1998). The second question is how people choose decision criteria. Subjects have been observed to shift their criterion when strength is varied between lists. When discrimination becomes easier, people adopt a higher standard of evidence. In other words, they adopt a more conservative criterion (Hirshman, 1995).

To understand the SPSD account for the present data, consider that in a familiarity-based model like the one 
described here, interference conditions should increase the mean strength (Dyne et al., 1990) and possibly the variance (Ratcliff, Sheu, \& Gronlund, 1992) of the old item familiarity distribution. This means that if subjects use the same remember criterion for all conditions, remember hits will increase with increasing interference. ${ }^{3}$ The decrease in remember hits observed in all three experiments implies instead that subjects used different remember criteria across conditions. In addition, in Experiments 1 and $3, d^{\prime}$ and remember hits both decreased with increasing interference. This implies that the remember criterion became more conservative as discrimination became harder. The SPSD account, therefore, relies on two claims, about the movement of decision criteria within a single test list and about the direction of this movement, that are at odds with what has previously been observed under somewhat similar conditions.

The weakness of the SPSD model in its current state does not stem from an inability to fit the data but rather from a lack of converging support from the relevant body of theory and findings that should serve to constrain the model, allowing it to explain and not merely describe remember-know data. The dual-process account proposed here is constrained by theory to predict how remember-know responses will change under interference conditions. Moreover, the account can be placed within a larger body of theory and converging evidence from various domains that support a qualitative distinction between remembering and knowing (for reviews, see Gardiner \& Richardson-Klavehn, 2000; Yonelinas, 2002).

\section{Dual-Process Account}

Another alternative view of remember-know judgment is agnostic with regard to the number of retrieval processes involved in recognition but suggests that subjective states are not tied to retrieval processes. Rather, the type of information labeled as remembered or known is context dependent (Bodner \& Lindsay, 2003; Dewhurst \& Conway, 1994; Whittlesea, 2002). This view is supported by findings that the rate of remember responses is not stable but can be manipulated with biasing instructions (Hirshman \& Henzler, 1998; Postma, 1999 ) and test list composition (Bodner \& Lindsay, 2003; Xu \& Bellezza, 2001) and also that ostensibly recollective information like memory for source can sometimes accompany know responses (Hicks et al., 2002; Perfect et al., 1996). As noted earlier, such findings are incompatible with the view that remembering is tied to a high-threshold or all-or-nothing recollection process.

They are, however, compatible with the view that remembering is tied to a recollection process that produces graded information. The idea that both specific and nonspecific memory is graded (Banks, 2000; Johnson, Hashtroudi, \& Lindsay, 1993; Rotello et al., 2004) suggests that subjects will vary their criterion for remember-know judgments just as they do for recognition judgments when conditions vary. For example, subjects may adopt a conservative criterion for saying "remember" when the memorable detail of test items is generally high or when instructed to do so; with a conservative remember criterion, subjects will sometimes say "know" even when some detail has been retrieved. This makes it problematic to draw conclusions about the absolute values of remember and know rates, and the comparison of values between tasks. The present approach, however, suggests that remember-know judgments may be useful as a way to compare the relative contributions of recollection and familiarity across classes of items when decision criteria remain fixed.

Although recollection and familiarity have been defined here as distinct processes, an alternative is to define them as different types of information (Johnson et al., 1993; Kelley \& Wixted, 2001). Either view can support the arguments that recognition is not based on a single form of information, that the relative contributions of recollection and familiarity change across tasks, and that the two forms of memory have different properties and can be affected differently by task manipulations. Thus, the distinction may not be critical for present purposes, and certainly in the wider literature the question remains unresolved. The process view was adopted here for two reasons. First, characterizations of the retrieval processes that already exist in the literature lead to a natural account of associative interference effects in recognition. Second, the focus on process allows memory tasks like recognition and recall, traditionally differentiated in terms of process, to be discussed within a single theoretical framework.

Recollection and familiarity were depicted in terms of their central characteristics, competitive selection and aggregation, respectively. Naturally, the processes must be more complex than this. Models of recall, for example, deal not only with the problem of selection but also that of recovery, converting noisy memory information into a usable response (Murdock, 1993; Raaijmakers \& Shiffrin, 1981; Rohrer, 1996). Although recovery may be minimally important in recognition, where the retrieval cue reinstates the memory item, the possibility that strongly associated competitors lead to facilitation rather than to interference during recovery might be examined (M. C. Anderson, Green, \& McCulloch, 2000; Nelson, McKinney, Gee, \& Janczura, 1998). As for familiarity, many theorists argue that inference and attribution play a critical role in how people interpret this information (Gruppuso, Lindsay, \& Kelley, 1997; Jacoby, Kelley, \& Dywan, 1989; Whittlesea, 2002). One way to think about these things is in terms of the processes by which people choose their response criteria. Such decision processes are compatible with the model of the familiarity process described here. It is possible that attribution processes may be more complex, requiring modification of the familiarity model, but this has not been well explored. The conclusion to be drawn from the present study is not that more complex models will not ultimately be necessary, but rather that the simple depictions of recollection and familiarity make for a meaningful, basic account of the findings. 
Is recall an appropriate model for recollection-based recognition? When comparing memory tasks, it is important to distinguish between surface differences (such as the quality of the retrieval cue or the form of the response) and differences in the underlying retrieval processes. Which of these is primarily responsible for the seemingly qualitative differences between recognition and recall remains an open question. However, the idea that recall sometimes plays a role in recognition certainly has intuitive appeal, and it has often been suggested informally (Clark, 1999; Mandler, 1980). Moreover, forms of recognition requiring very specific information, like associative recognition, can behave in ways that resemble recall more than item recognition (Clark, 1992; Nobel \& Shiffrin, 2001; Verde \& Rotello, 2004), giving credence to the idea that memory tasks differ along a continuum. As in the present study, making explicit the relationship between recall and recognition may prove useful in testing theories of recognition.

\section{REFERENCES}

Anderson, J. R., \& Reder, L. M. (1999). The fan effect: New results and new theories. Journal of Experimental Psychology: General, 128, 186-197.

ANDERson, M. C., Green, C., \& McCulloch, K. C. (2000). Similarity and inhibition in long-term memory: Evidence for a two-factor theory. Journal of Experimental Psychology: Learning, Memory, \& Cognition, 26, 1141-1159.

ANISFIELD, M., \& KNAPP, M. (1968). Association, synonymity, and directionality in false recognition. Journal of Experimental Psychology, 77, 171-179.

ATKINSON, R. C., \& JUOLA, J. F. (1974). Search and decision processes in recognition memory. In D. H. Krantz, R. C. Atkinson, R. D. Luce, \& P. Suppes (Eds.), Contemporary developments in mathematical psychology (pp. 243-293). San Francisco: Freeman.

BANKs, W. P. (2000). Recognition and source memory as multivariate decision processes. Psychological Science, 11, 267-273.

BoDNER, G. E., \& LiNDSAY, D. S. (2003). Remembering and knowing in context. Journal of Memory \& Language, 48, 563-580.

Bransford, J. D., \& Franks, J. J. (1971). The abstraction of linguistic ideas. Cognitive Psychology, 2, 331-350.

Busey, T. A., \& TunNiclifF, J. L. (1999). Accounts of blending, distinctiveness, and typicality in the false recognition of faces. Journal of Experimental Psychology: Learning, Memory, \& Cognition, 25, 1210-1235.

CANTOR, J., \& Engle, R. W. (1993). Working-memory capacity as long-term memory activation: An individual-differences approach. Journal of Experimental Psychology: Learning, Memory, \& Cognition, 19, 1101-1114.

CLARK, S. E. (1992). Word frequency effects in associative and item recognition. Memory \& Cognition, 20, 231-243.

Clark, S. E. (1999). Recalling to recognize and recognizing to recall. In C. Izawa (Ed.), On human memory: Evolution, progress, and reflections on the 30th anniversary of the Atkinson-Shiffrin model (pp. 215-243). Mahwah, NJ: Erlbaum.

Clark, S. E., \& Gronlund, S. D. (1996). Global matching models of recognition memory: How the models match the data. Psychonomic Bulletin \& Review, 3, 37-60.

Cleary, A. M., Currân, T., \& Greene, R. L. (2001). Memory for detail in item versus associative recognition. Memory \& Cognition, 29, 413-423.

Conway, M. A., \& Dewhurst, S. A. (1995). Remembering, familiarity, and source monitoring. Quarterly Journal of Experimental Psychology, 48A, 125-140.

Curran, H. V., GARDiner, J. M., JaVA, R. I., \& Allen, D. (1993). Effects of lorazepam upon recollective experience in recognition memory. Psychopharmacology, 110, 374-378.
Dewhurst, S. A., \& Conway, M. A. (1994). Pictures, images, and recollective experience. Journal of Experimental Psychology: Learning, Memory, \& Cognition, 20, 1088-1098.

Dodson, C. S., Holland, P. W., \& Shimamura, A. P. (1998). On the recollection of specific- and partial-source information. Journal of Experimental Psychology: Learning, Memory, \& Cognition, 24, $1121-1136$

DonALDSON, W. (1996). The role of decision processes in remembering and knowing. Memory \& Cognition, 24, 523-533.

Duzel, E., Yonelinas, A. P., Mangun, G. R., Heinze, H., \& TulVING, E. (1997). Event-related brain potential correlates of two states of conscious awareness in memory. Proceedings of the National Academy of Sciences, 94, 5973-5978.

Dyne, A. M., Humphre Ys, M. S., Bain, J. D., \& Pike, R. (1990). Associative interference effects in recognition and recall. Journal of Experimental Psychology: Learning, Memory, \& Cognition, 16, 813824.

FLAGG, P. W. (1976). Semantic integration in sentence memory. Journal of Verbal Learning \& Verbal Behavior, 15, 491-504.

GARDINER, J. M., \& GREGG, V. H. (1997). Recognition memory with little or no remembering: Implications for a detection model. Psychonomic Bulletin \& Review, 4, 474-479.

GARDINER, J. M., RAMPONI, C. \& RichaRdSON-KLAVEHN, A. (1998). Experiences of remembering, knowing, and guessing. Consciousness \& Cognition, 7, 1-26.

GaRdiner, J. M., \& RichaRdSON-KLAVEhN, A. (2000). Remembering and knowing. In E. Tulving \& F. I. M. Craik (Eds.), The Oxford handbook of memory (pp. 229-244). New York: Oxford University Press.

Gillund, G., \& ShIFFrin, R. M. (1984). A retrieval model for both recognition and recall. Psychological Review, 91, 1-67.

Gruppuso, V., Lindsay, D. S., \& Kelley, C. M. (1997). The processdissociation procedure and similarity: Defining and estimating recollection and similarity in recognition memory. Journal of Experimental Psychology: Learning, Memory, \& Cognition, 23, 259-278.

Heit, E., BrockdorfF, N., \& Lamberts, K. (2003). Adaptive changes of response criterion in recognition memory. Psychonomic Bulletin \& Review, 10, 718-723.

HENKEL, L. A., \& FRANKLIN, N. (1998). Reality monitoring of physically similar and conceptually related objects. Memory \& Cognition, 26, 659-673.

HicKS, J. L., MARSH, R. L., \& RitsCheL, L. (2002). The role of recollection and partial information in source monitoring. Journal of Experimental Psychology: Learning, Memory, \& Cognition, 28, 503-508.

HintzMan, D. L. (1988). Judgments of frequency and recognition memory in a multiple-trace memory model. Psychological Review, 95, 528-551.

Hintziman, D. L., Caulton, D. A., \& Levitin, D. J. (1998). Retrieval dynamics in recognition and list discrimination: Further evidence of separate processes of familiarity and recall. Memory \& Cognition, 26, 449-462.

HiNTZMAN, D. L., \& CuRRAN, T. (1994). Retrieval dynamics of recognition and frequency judgements: Evidence for separate processes of familiarity and recall. Journal of Memory \& Language, 33, 1-18.

HiRshman, E. (1995). Decision processes in recognition memory: Criterion shifts and the list-strength paradigm. Journal of Experimental Psychology: Learning, Memory, \& Cognition, 21, 302-313.

HIRSHMAN, E. (1998). On the utility of the signal detection model of the remember-know paradigm. Consciousness \& Cognition, 7, 103-107.

Hirshman, E., \& Henzler, A. (1998). The role of decision processes in conscious recollection. Psychological Science, 9, 61-65.

Hirshman, E., \& Master, S. (1997). Modeling the conscious correlates of recognition memory: Reflections on the remember-know paradigm. Memory \& Cognition, 25, 345-351.

HoCKLEY, W. E., \& CoNSOLI, A. (1999). Familiarity and recollection in item and associative recognition. Memory \& Cognition, 27, 657-664.

HockLEY, W. E., \& NIEWIADOMSKI, M. W. (2001). Interrupting recognition memory: Tests of a criterion-change account of the revelation effect. Memory \& Cognition, 29, 1176-1184.

Holmes, J. B., Waters, H. S., \& RaJaram, S. (1998). The phenomenology of false memories: Episodic content and confidence. Journal of Experimental Psychology: Learning, Memory, \& Cognition, 24, 1026-1040. 
Humphreys, M. S. (1978). Item and relational information: A case for context independent retrieval. Journal of Verbal Learning \& Verbal Behavior, 17, 175-187.

Humphreys, M. S., Pike, R., Bain, J. D., \& Tehan, G. (1989). Global matching: A comparison of the SAM, Minerva, and Matrix and TODAM models. Journal of Mathematical Psychology, 33, 36-67.

Inoue, C., \& Bellezza, F. S. (1998). The detection model of recognition using know and remember judgments. Memory \& Cognition, 26, 299-308.

JaCOBY, L. L., Kelley, C. M., \& Dywan, J. (1989). Memory attributions. In H. L. Roediger III \& F. I. M. Craik (Eds.), Varieties of memory and consciousness: Essays in honour of Endel Tulving (pp. 391422). Hillsdale, NJ: Erlbaum.

Johnson, M. K., Hashtroudi, S., \& Lindsay, D. S. (1993). Source monitoring. Psychological Bulletin, 114, 3-28.

JoORdENs, S., \& HockLEY, W. E. (2000). Recollection and familiarity through the looking glass: When old does not mirror new. Journal of Experimental Psychology: Learning, Memory, \& Cognition, 26, 1534-1555.

KeLley, R., \& Wixted, J. T. (2001). On the nature of associative information in recognition memory. Journal of Experimental Psychology: Learning, Memory, \& Cognition, 27, 701-722.

KING, D. R. W., \& ANDERSON, J. R. (1976). Long-term memory search: An intersecting activation process. Journal of Verbal Learning \& Verbal Behavior, 15, 587-605.

Koutstaal, W., \& Schacter, D. L. (1997). Gist-based false recognition of pictures in older and younger adults. Journal of Memory \& Language, 37, 555-583.

KUČERA, F., \& FRANCIS, W. (1967). Computational analysis of presentday American English. Providence, RI: Brown University Press.

MANDLER, G. (1980). Recognizing: The judgment of previous occurrence. Psychological Review, 87, 252-271.

Mather, M., Henkel, L. A., \& Johnson, M. K. (1997). Evaluating characteristics of false memories: Remember/know judgments and memory characteristics questionnaire compared. Memory \& Cognition, 25, 826-837.

MCElREE, B., Dolan, P. O., \& JACOBY, L. L. (1999). Isolating the contributions of familiarity and source information to item recognition: A time course analysis. Journal of Experimental Psychology: Learning, Memory, \& Cognition, 25, 563-582.

Medin, D. L., \& Schaffer, M. M. (1978). Context theory of classification learning. Psychological Review, 85, 207-238.

Morrell, H. E. R., Gaitan, S., \& WIXTED, J. T. (2002). On the nature of the decision axis in signal-detection-based models of recognition memory. Journal of Experimental Psychology: Learning, Memory, \& Cognition, 28, 1095-1110.

MURDOCK, B. B., JR. (1993). TODAM2: A model for the storage and retrieval of item, associative, and serial-order information. Psychological Review, 100, 183-203.

Nelson, D. L., McKinney, V. M., Gee, N. R., \& Janczura, G. A. (1998). Interpreting the influence of implicitly activated memories on recall and recognition. Psychological Review, 105, 299-324.

Nobel, P. A., \& ShIFFrin, R. M. (2001). Retrieval processes in recognition and cued recall. Journal of Experimental Psychology: Learning, Memory, \& Cognition, 27, 384-413.

Perfect, T. J., Mayes, A. R., Downes, J. J., \& Van Eijk, R. (1996). Does context discriminate recollection from familiarity in recognition memory? Quarterly Journal of Experimental Psychology, 49A, 797-813.

PostMa, A. (1999). The influence of decision criteria upon remembering and knowing in recognition memory. Acta Psychologica, 103, $65-$ 76.

Postman, L. (1976). Interference theory revisited. In J. Brown (Ed.), Recall and recognition (pp. 157-182). New York: Wiley.

RaAimakers, J. G. W., \& Shiffrin, R. M. (1981). Search of associative memory. Psychological Review, 88, 93-134.

RatClifF, R., SHEU, C., \& GRONLUND, S. D. (1992). Testing global memory models using ROC curves. Psychological Review, 99, 518-535.

REDER, L. M., \& ANDERSON, J. R. (1980). A partial resolution of the paradox of interference: The role of integrating knowledge. Cognitive Psychology, 12, 447-472.
Reder, L. M., Angstadt, P., Cary, M., Erickson, M. A., \& Ayers, M. S. (2002). A reexamination of stimulus-frequency effects in recognition: Two mirrors for low- and high-frequency pseudowords. Journal of Experimental Psychology: Learning, Memory, \& Cognition, 28, 138-152.

ReDer, L. M., Nhouyvanisvong, A., Schunn, C. D., Ayers, M., Angstadt, P., \& Hiraki, K. (2000). A mechanistic account of the mirror effect for word frequency: A computational model of rememberknow judgments in a continuous recognition paradigm. Journal of Experimental Psychology: Learning, Memory, \& Cognition, 26, 294320.

Reitman, J. S., \& Bower, G. H. (1973). Storage and later recognition of exemplars of concepts. Cognitive Psychology, 4, 194-206.

Roediger, H. L., III, \& McDermott, K. B. (1995). Creating false memories: Remembering words not presented in lists. Journal of Experimental Psychology: Learning, Memory, \& Cognition, 21, 803-814.

ROHRER, D. (1996). On the relative and absolute strength of a memory trace. Memory \& Cognition, 24, 188-201.

Rotello, C. M., \& Heit, E. (2000). Associative recognition: A case of recall-to-reject processing. Memory \& Cognition, 28, 907-922.

Rotello, C. M., Macmillan, N. A., \& Reeder, J. A. (2004). Sumdifference theory of remembering and knowing: A two-dimensional signal detection model. Psychological Review, 111, 588-616.

RugG, M. D., SchloerscheidT, A. M., \& MARK, R. E. (1998). An electrophysiological comparison of two indices of recollection. Journal of Memory \& Language, 39, 47-69.

RUNDUS, D. (1973). Negative effects of using list items as recall cues. Journal of Verbal Learning \& Verbal Behavior, 12, 43-50.

ShIFFrin, R. M., HubER, D. E., \& MARINELli, K. (1995). Effects of category length and strength on familiarity in recognition. Journal of Experimental Psychology: Learning, Memory, \& Cognition, 21, 267287.

Strack, F., \& Bless, H. (1994). Memory for nonoccurrences: Metacognitive and presuppositional strategies. Journal of Memory \& Language, 33, 203-217.

Stretch, V., \& Wixted, J. T. (1998). On the difference between strength-based and frequency-based mirror effects in recognition memory. Journal of Experimental Psychology: Learning, Memory, \& Cognition, 24, 1379-1396.

Tulving, E. (1985). Memory and consciousness. Canadian Psychology, 26, 1-12.

UNDERWOOD, B. J. (1965). False recognition produced by implicit verbal responses. Journal of Experimental Psychology, 70, 122-129.

VERDE, M. F. (2004). The retrieval practice effect in associative recognition. Memory \& Cognition, 32, 1265-1272.

Verde, M. F., \& Rotello, C. M. (2003). Does familiarity change in the revelation effect? Journal of Experimental Psychology: Learning, Memory, \& Cognition, 29, 739-746.

Verde, M. F., \& Rotello, C. M. (2004). Strong memories obscure weak memories in associative recognition. Psychonomic Bulletin \& Review, 11, 1062-1066.

VoGT, J., \& KimbLe, G. A. (1973). False recognition as a function of associative proximity. Journal of Experimental Psychology, 99, 143145.

VoKEY, J. R., \& READ, J. D. (1992). Familiarity, memorability, and the effect of typicality on the recognition of faces. Memory \& Cognition, 20, 291-302.

WESTERMAN, D. L. (2000). Recollection-based recognition eliminates the revelation effect in memory. Memory \& Cognition, 28, 167-175.

WeSterman, D. L. (2001). The role of familiarity in item recognition, associative recognition, and plurality recognition on self-paced and speeded tests. Journal of Experimental Psychology: Learning, Memory, \& Cognition, 27, 723-732.

W HitTLESEA, B. W. A. (2002). Two routes to remembering (and another to remembering not). Journal of Experimental Psychology: General, 131, 325-348.

WhitTlesea, B. W. A., \& Williams, L. D. (2001). The discrepancyattribution hypothesis: I. The heuristic basis of feelings of familiarity. Journal of Experimental Psychology: Learning, Memory, \& Cognition, 27, 3-13.

WiXTED, J. T., GHADisha, H., \& Vera, R. (1997). Recall latency fol- 
lowing pure- and mixed-strength lists: A direct test of the relative strength model of free recall. Journal of Experimental Psychology: Learning, Memory, \& Cognition, 23, 523-538.

XU, M., \& BellezZA, F. S. (2001). A comparison of the multimemory and detection theories of know and remember recognition judgments. Journal of Experimental Psychology: Learning, Memory, \& Cognition, 27, 1197-1210.

YONELINAS, A. P. (1994). Receiver-operating characteristics in recognition memory: Evidence for a dual-process model. Journal of Experimental Psychology: Learning, Memory, \& Cognition, 20, 13411354.

Yonelinas, A. P. (1997). Recognition memory ROCs for item and associative information: The contribution of recollection and familiarity. Memory \& Cognition, 25, 747-763.

YoneLinAS, A. P. (2002). The nature of recollection and familiarity: A review of 30 years of research. Journal of Memory \& Language, $\mathbf{4 6}$, 441-517.

YoNelinAS, A. P., \& JACOBY, L. L. (1995). The relation between remembering and knowing as bases for recognition: Effects of size congruency. Journal of Memory \& Language, 34, 622-643.

\section{NOTES}

1. Aggregation might be described as the sum or product of individual cue-to-memory matches, although the specific transformation is unimportant for purposes of this article. The discrete-memory model is adopted for ease of exposition, but similar predictions can be made for composite-memory models (Humphreys, Pike, Bain, \& Tehan, 1989).

2. However, familiarity can still influence associative recognition judgments (Cleary, Curran, \& Greene, 2001; Kelley \& Wixted, 2001).

3. Assuming a Gaussian distribution, as mean strength and possibly variance increase, a greater proportion of the distribution will exceed the criterion. Although this might not be true if variance increases greatly relative to strength and the criterion is set below the mean of the distribution, in all cases the interference condition remember criterion was set above the mean, indicated by remember hit rate $<.50$.

(Manuscript received February 3, 2003; revision accepted for publication April 15, 2004.) 